\title{
The Influence of the Student-oriented Multimodal Teaching Mode to Students' Uptake Offline
}

\author{
Xinyu Liu ${ }^{1, *, \dagger}$ Weiwei Zhang ${ }^{2, *, \dagger}$ Guang Yang ${ }^{3, *, \dagger}$ \\ ${ }^{1}$ Department of foreign languages, Nankai University binhai College, Tianjin, Tianjin, 300451, China \\ ${ }^{2}$ College of Foreign Languages, Nanjing University of Aeronautics and Astronautics, Nanjing, Jiangsu, 211106, \\ China \\ ${ }^{3}$ School of Foreign Studies, Capital University of Economics and Business, Beijing, Beijing, 100070, China \\ *Corresponding author. Email: ${ }^{1}$ glorialxy123@163.com, ${ }^{2}$ zhang.weiwei@nuaa.edu.cn, ${ }^{3}$ beckyyang2001@163.com
}

These authors contributed equally.

\begin{abstract}
In current decade, both students and teachers are paying more and more attention on the quality of class, which includes students' uptake, communication, students' feelings and so on. It is necessary to provide some suggestions to teachers for assisting them to build up a better class. This paper explores a class video which holds the student-oriented multimodal teaching mode in order to explore the methods that can be used by teachers to organize a better class. Through the conversation analysis and the gesture analysis of a video, we find that there are lots of teachers' characteristics, which could be useful. And then we transcribed them in details and concluded three important findings. The first is repeats, which can be helpful for giving students' guidance and structuring the class efficiently. Then, this paper also find that eye contact is one of the frequent ways in teacher-student interactions, which can improve the quality of communication between teachers and students. It promotes students feel at home when teachers can use eye contacts effectively. Besides, further questions from both teachers and students will lead students expand their minds and have more learning opportunity. These three aspects concluded by this class's findings can also be transferred to other educational settings, which is useful and practicable for the field of educational research. By analysing this specific video with detailed transcripts, it is convincible to observe this class specifically. Moreover, these three aspects concluded by this class's findings can also been transferred into other educational settings, which is useful and practicable for the educational research field.
\end{abstract}

Keywords: Student-oriented Multimodal Teaching Mode, Questioning, Eye-contact, Repeat, Classroom Interactions, Teacher Discourse

\section{INTRODUCTION}

This paper reviews the influence of students-oriented multimodal teaching modes on students' uptakes offline, which aims at emphasizing the importance of interactions and raising the awareness of teachers and researchers to classroom interactions. The treatise reflects some of the current situations of Chinese classroom and foreign classroom. Chinese classroom is teacher-centred, while foreign classroom is more student-centred. Therefore, interaction in Chinese classroom is often ignored, which should be taken seriously. This paper investigates how can teachers in offline classrooms mobilize students to think actively and promote the progress of courses. We adopt the method of conversation analysis to conduct specific analysis and research on the interactions between teachers and students. Through the analysis, we come up with some interesting findings. In this review, it refers to three necessary findings, including eye contact, repeats and questioning.

\section{LITERATURE REVIEW}

\subsection{The Zone of Proximal Development (ZPD)}

One major aspect of Vygotsky (1978)'s theory is the idea that the potential for cognitive development depends upon the "ZPD": Vygoski divides the development of children into the following three areas. The first area is the current level of students, which refers to the problem- 
solving level that can be achieved by independent activities; the second one is the possible development level of students, which is the potential gained through teaching. The area between these two areas is the zone of proximal development.

Vygotsky argues that: "when children interact with adults, children's basic mental function develop into more advanced and complex cognitive one" [1]. For instance, two children may have the same IQ (Intelligence Quotient) score, indicating that they have reached the same level of development and are therefore ready to attend classes, but one of them may be able to perform more complex tasks than the other with the same assistance of the teacher. Different from Vygotsky's theory, Piaget (1980)'s "irrelevance theory" points out that teaching and child development are basically unrelated. Teaching will neither promote the developing speed of children, nor change the direction of their development. What it can achieve best is that it will only use the achievements of children's intellectual development. If teachers only focus on the external teaching to improve children's developmental ability, it will definitely ignore the active constructively of children in the developing process. I support Vygotsky's theory even more. Although Piaget's theory is reasonable, teaching does need to first consider the level of development that children have now reached. However, only considering that level and obliterating the positive role that teaching can play is also unrealistic.

\subsection{Repeat}

In the New Oxford Dictionary, "Repeat" may refer to: say again something one has already said or do (something) again. According to Mou, there are roughly two definitions of repetition in the academic area. One is that repetition is copying, which means the sound and form of speech are completely repetitive [2]. It often occurs in daily conversations between people. For example, A: "Do you love me?" B: "Yes." A: "Do you love me?" B: "Of course." The other shows that repetition means recurrence. That is, words that express the same meaning appear in different places in the article. Mou argues that analysed from a micro perspective, repetition has the functions of confirmation, clarification, emphasis and feedback [2]. During the class, teacher will ask students "Are you clear?" repeatedly to confirm whether they are understanding or not. An holds the view that repetition is an approach by which the speaker expresses his attitude, certain emotions and feelings [4]. For example, when people are surprised, they will express their feelings by saying "Really?" repeatedly. At the same time, Mou refers that repetition may also cause communication barriers [2]. The specific performance is generally the extension of communication time and the decrease of communication efficiency. In the offline class, teacher keeps repeating one same point will reduce classroom efficiency.

\subsection{Eye Contact}

Eye contact happens when people look at each other directly, which expresses nonverbal information efficiently. Eye contact is one of the basic branches of multimodal classroom mode, which can lead to a high efficiency and comfortable class. That is to say, teachers' reasonable using of non-verbal will effectively improve the quality of classroom interaction [5]. Wheeler suggested that eye contact has a positive effect on the establishment of a harmonious teacher-student relationship, and it is a decisive nonverbal clue that implies a positive emotional state [6]. Rosa and others believe that the eyes are an important tool for non-verbal behaviour, and the teacher-student relationship in the classroom is often established and maintained by the eyes [7]. Different with verbal communication and gesture in classroom, which can be easily noticed by people, eye contact is too slight to be firstly paid attention to. But it is no doubt that eye contact between teacher and students is an important component of a good class.

When came to the positive effects of eye contact through the class, Hodge argues that "when one person's eyes are 'locked in' with another's, those two peopleand only those two people-share that communication" [8]. That means teachers can check if students have fully understood the class content, and students can also reply by eye contact. Instead of asking the whole class one by one, just looking around to check students' comprehension is a more efficient way. The similar opinion can be seen that eye contact "provided opportunities to learn coping strategies to build the capacity of student" [9], which also give the idea that eye contact gives teachers the information about the students' condition in the class, and give teachers an opportunity to reorganize the class into an easily-understand one. Secondly, Gu argues that eye contact can easily arrest the attention of a student, and can even be powerful enough to convey such messages as "keep talking" and "stop talking" [6], which gains the power from the statement that eye contact "projects his presence through teacherstudent eye contact, using appropriate timing and intensity" [8]. Their ideas mean that eye contact in class can perform as a notice or warning to encourage students to be more concentrated, which will lead to a class with high efficiency, that is, teachers' words can be fully understand by students in time and students can indulge in the class and gain something. Besides, $\mathrm{Xu}$ and Xiong hypothesized that there are five main functions of teachers' eye contacts with during classes: giving students a sense of care and awareness; discovering the emotional status of students; transmitting a sense of responsibility and trust; identifying each student's uniqueness; and giving students a sense of respect [11]. 
All of these functions are focusing on students' feelings in class. When teacher's eye contact attaches them, they will feel that they are concerned and cared. They will feel that they are really involved in the class, and they are necessary and couldn't be ignored. And these kinds of feelings will not only encourage students more willing to learn, but also will create a comfortable and active atmosphere.

\subsection{The Improvement of Students' Uptake by Asking Questions}

The way of questioning can be divided into two parts: Content question and form question. Content question refers to asking questions about what students or teachers are confused about. Form question is question about writing formats, such as grammatical form, paper format and other types like this. Through the conversation analysis, we assume that both teachers' questions and students' questions have positive and negative effects on improving students' uptake.

\subsubsection{Teacher's question}

Initially, teacher's questions can check students' comprehensions of classroom content. Kelly, a primary school teacher, modified instruction based on comprehension needs of her students and modelled questioning as one facet of comprehension [12]. It can be learned that the teachers' questions can help students improve their comprehensions. Moreover, teachers prevent students from limiting thinking by asking questions, thus promoting students' thinking space. When questions were open-ended, students employed a more varied vocabulary and more complex sentence structures. When teachers' questions were oriented toward prediction and reasoning, students practiced these higher-level cognitive skills in responding [13]. Therefore, teachers' question is also a very necessary element to improve their learning space.

\subsubsection{Students' question}

Students' question also provides many benefits to learning. Generally speaking, asking question can help students solve their doubts in time. Asking questions guide students' learning as they tend to make sense new information based on their former knowledge [14]. This avoids the irritable mood of students who cannot solve problems in time. Hence, students can maintain a positive attitude towards new knowledge. In addition, students' question can improve the teacher's preparations for the course. Student questioning actually has influences on school's course [14]. This means that the teacher can adjust the classroom contents according to students' needs. Hence, the students can follow the progress of the class better.
However, some important drawbacks of questioning cannot be ignored. Some students do not like asking questions. Then they choose to give up asking questions. Studies at different educational levels and contexts generally indicate that learners avoid asking questions. The number and kind of questions that learners ask may be influenced by previous knowledge, experiences and skills, their age, the attitude of the teacher, teaching style, classroom evaluative climate, social interaction patterns and nature of the topics [14]. This may cause students lose interest in the course and is not conducive to promoting them to broaden their mind.

\section{RESULT AND DISCUSSION}

\subsection{Repetition}

3.1.1. The repetition of the teacher's words in the classroom can arise the classroom atmosphere and make students more concentrate.

From 0:37 to the end of the clip, the teacher repeated the sentence "This is what we do." for three times. The tone of each time was stronger than the previous one, and the duration of the ending sound gradually became longer.

$27 \quad(($ rubs his hands $))]$

$28 \quad$ ((clasps his

29 hands) $)]=$

29 Stu: $=[(($ laughing $))$

30 Tea: ((opens her arms) $)^{\circ}$ That's what we do, $\mathrm{Ja}^{\wedge} \mathrm{ke}^{\circ}(0.7)$ This is

what we do:::(0.7)

These three sentences pushed the atmosphere of the classroom to a climax. Every student paid his or her attention to the teacher and raised their hands to cheer or applaud.

Mou argues that repetition can adjust the atmosphere of communication [2]. Sometimes, repetition is to achieve the effect of humour, and humour has the effect of easing the communicative atmosphere. The repetitive sentence is usually louder and has more stress than ordinary sentences. This attracts the listener's attention, thereby deepening the listener's impression. In the offline classroom, teacher's repetition allows students to focus on him or her and makes students have a better understanding of the lesson, thus achieving the effect of adjusting the classroom atmosphere. 
3.1.2. Repetition can emphasize teacher's discourse, manage the class time efficiently and allows students to grasp the key points of the lesson.

At 4:52 of the full video, the teacher repeated the word "so" for three times to emphasize the importance of Stakeholder analysis to the students. Every repetition puts the stress on this word, and the intensity of the tone gradually increases.

01 Tea: ((slightly shake her hands)) Stakeholder analysis (is) so::, $\mathrm{s}^{\wedge} \mathrm{o}$ : importan- when (we) think abouchange.

$02 \quad \mathrm{~S}^{\wedge} \mathrm{o}:::$ importan- to (do).

After saying this sentence, the teacher commented on the students' previous answers. She pointed out the loopholes and deficiencies in the answers of students, while expressing her own thoughts and some guiding opinions. Chen and Liu argue that teacher draws the attention of students by emphasizing some words or phrases, and emphasizes the key and difficult points of this part, which allow students to clearly understand this problem and promote their understanding [3]. The teacher in this video asked the students several major questions about this case and asked them to think from multiple angles, which effectively controlling the progress of the class and also allows students to grasp the key points of this lesson.

\subsubsection{Repetition can help teacher to facilitate students and induce them to answer the question.}

At 2:33 of the complete video, after one student expressed his opinion, the teacher turned to ask others who opposed it on this issue. This Interrogative sentence was repeated twice.

01 Tea: ((opens her arms)) Bu- those o- you whdisagree say what?

\section{Those o- you disagree say wha-,Will?}

Chen points out that repetition can induce answers [3]. The wonderful thing about teacher-student dialogue in English classrooms lies in the unknown and generation of the dialogue. The information of the students' words will trigger new thinking by the teachers. When the teacher repeats the words of the students, they will create more thinking spaces for them. While radiating with the distance, it is important to achieve a harmonious dialogue between teachers and students.

In this class, the main purpose of the teacher's use of repetitive sentences here is to induce students to answer questions. By repeating the question to extend the students' thinking space on this question, it is necessary to further stimulate the enthusiasm of students to answer this question.

\subsection{Eye contact}

\subsubsection{Through eye contact teachers can communicate with students easily and conveniently.}

In the video, we can see that through eye contact teacher quickly found that there were some students who had not understand Jake's words, so she asked Jake to repeat.

01 Tea: They don'- get i-, Jake. ((Point to Jake))

Then Jake started to reexplain his idea and there were some eye contacts between Jake and teacher and his classmates. And finally, we can see that Cynthia was nodding and smile.

\section{Cyn: $[(($ nod and smile $))$}

We can also see that students are doing the same thing. These actions lasted for several seconds and repeated several times, which can totally reveal that all of them finally understood their classmates after his repetition asked by the teacher. And this also means that the teacher-student communication through eye contact was successful.

This kind of success comes from a basic awareness that eye contact is a form of interpersonal communication, and usually accompanied by a nod of a head or a smile, eye contact can also communicate greetings just as our verbal languages do [10]. Therefore, the information can always be conveyed through eyes. Gu also said that due to the fact that a successful instruction is largely dependent upon individual receptivity [10]. That is to say, the communication is so important to make students and teachers know each other's condition and reply them in the most quickly but exactly way.

Another example appeared when Jake could not answer the question from teacher and want to say something to cover it. And then the teacher looks around the class, which means there would be eye contact with all the other students, and students get the information from their teacher that she was making fun of Jake, then the whole class burst into laugh.

31 Stu: [((laughing and clapping their hands))

Therefore, we can get to know that they totally get the information, which prove the communication's efficiency again.

\subsubsection{Eye contact can make students feel that they are cared and a significant part of the class.}

When Jake was speaking, the teacher kept her eyes on him continuously.

10 Tea: ((Listening carefully))] 
From this video, it is obvious that the teacher was listening carefully, which can be concluded from the teacher's eyes. Before the teacher's staring, Jake was expressing his idea without any gesture. But then, after the eye touching, we found that Jake explained his view in a more energetic way that he had more gestures like stretching his hands or pointing the blackboard. Also, he had greater expression such as raising his eyebrow.

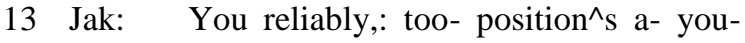
previous company^,

14 you were incredibly unpopular^] (0.4) anencountere-

15 all: sorts o- resistan^ ${ }^{\wedge}$ ce. An- I think this is a case,

16 where [you. show me: you can do $\left[\mathrm{i}^{\wedge}\right.$-(an-) so I woulshut down ${ }^{\circ}$ the com $^{\circ}$. ((stretch out hands)) ((Point to blackboard))]

We can make the conclusion that teachers' eyes had given him something like confidence, encouraging him to speak more.

And again, the example when Jake failed to make an answer. Before that, the conversation seemed to take place just between teacher and Jake: Jake said his idea and the teacher challenged him. They were absolutely the two sides of the communication. But teachers' eye contact with all of them through the around-seeing make them feel they were a part of class. So, they burst into laugh, kind of an interaction with teacher, which showed that they knew they were a part and so that they should make some response. Hodge said, "the eyes confirm that the teacher is alive, awake and presumably alert" [8]. Eye contact gives teacher a way to tell students that he or she still remember them. By indicating the awareness of student's existence, teacher give students the feeling of respect through eye contact [11]. Then the student's inner world will be so comfortable that they will have more energy to learn.

\subsection{Questions were raised based on student- oriented class}

Below are two questions were raised by the teacher in this video clip:

At the beginning of the clip, the teacher called a student's name to ask his opinions on the question of "as a CEO of the world's largest mining companies, when two miners have lost their life in succession, you should decide whether to shut down the mine or continue business as usual." This kind of question will lead students more focused because they must be ready to answer the question. In addition, in the process of answering questions, students' mind is also running, which makes their mind in a highly concentrated and active state. This is helpful for students to have more interests in classroom participation.

01 Tea: They don't get it, Jake. (Point to Jake)

After this, when this student finished his talk about the given case, the teacher asked him several questions: "This situation is different, don't you think? Is she suited for this job? Can she do this?" And then Jake, who was so confidence about his idea before, started to think again through the direction given by the teacher. And these detractions were definitely things he never thought before. In this situation, the teacher urged the students to think in a more complete way by asking further questions. Students can explore the viewpoints they did not expect, experience the change of their position, and prompt them to think about the loopholes in their own viewpoints that they did not expect. At the same time, follow-up questions can drive students into the direction of the main subject of the classroom, and guide students to explore the subject through these further questions, making learning and thinking more efficient.

19 Tea: This situation is different, don't you think?

20 Is she suited for this job? Can she do this?

21 (slightly shakes her hands)

Moreover, from the clip we can found that most of the class time is left for students, and only a small part for teachers to ask questions. That presents us a completely student-oriented class. It fully embodies the student authority, which should be used for a decent reference by teachers. In many normal classes we have known, most of the time is for teachers to spread knowledge individually, leaving students little time or even no time to exchange ideas or make debate. In another word, students are passively acquiring knowledge. To some extent, it limits students' right to think independently. Apparently, such classes are not focused on student authority.

In the class we analysed, student's speech occupied most of the time. The teacher pushes students to raise their opinions by asking question, and she spends most of the time to do this. In the second part of teacher's question, the teacher asks this student several questions about his speech. It forces students to think deeply, to think about risks, to think about their weaknesses in their ideas, and to also listen to others' views. All these are spontaneous behaviours of students, instead of the onesided export of knowledge through teachers, which greatly guarantee the student's authority. It encourages students to own critical thinking, which is helpful for their improvements. 


\section{CONCLUSION}

In this review, we mainly analyse the influence of the Student-oriented Multi-modal Teaching Mode on Students' uptakes in offline classrooms. Three interaction modes of teachers in American class context are discussed: repeat, eye contact and questioning. Our findings argue that: 1) the repetition of the teacher's discourse can play a role in adjusting the classroom progress while guiding students; 2) eye contact is one of the basic elements of the multi-modal classroom teaching mode, which can lead the whole class step by step in an efficient and relaxed way; 3 ) through teacher and student questioning, students' uptake can be improved in the offline classroom. In the future, more teachers and educators can adopt this kind of student-centered multimodal teaching method to improve teaching quality and teaching methods. Through our research, teachers can have a deeper understanding of the multi-modal teaching method, and improve their teaching level from the aspects of discourse, gestures, eye-contacts and so on. In addition, they can also learn from the comparison of classroom teaching between the Western studentoriented and Chinese teacher-centred offline to develop teaching standards. For educational researchers, our research can inspire future research on the importance of student-centred classroom and the development in this educational field.

\section{REFERENCES}

[1] Tayebeh \& Farid (2011). Implications of Vygotsky's Zone of Proximal Development (ZPD) in Teacher Education: ZPTD and Self-scaffolding. Retrieved from

https://www.sciencedirect.com/science/article/pii/S 1877042811028631

[2] Wenting (2016, April). An Analysis of the Functions and Restricting Factors of the Repeated Utterances in Conversation. Retrieved from https://kns.cnki.net/kcms/detail/detail.aspx?dbcode $=$ CMFD $\&$ dbname $=$ CMFD201701 $\&$ filename $=1016$ 086638.nh\&v=cS5kKM0kvfqjDo6CxbUbLwQwij 11BRXWTbao\%25mmd2BJlQBcxOl8HPz3\%25m md2BIVAaUz8OsZyo0

[3] Liqin \& Yang (2017, February). A Corpus-based Contrastive Study of Repetition of English Teachers in Senior Middle Schools. Retrieved from https://kns.cnki.net/kcms/detail/detail.aspx?dbcode $=$ CJFD $\&$ dbname $=$ CJFDLAST2017 $\&$ filename $=$ SD WG201701002\&v=c4HpL3FPS8aHtU\%25mmd2B PmnS0BcnODj06bPz $\% 25 \mathrm{mmd} 2 \mathrm{FfOxL} \% 25 \mathrm{mmd} 2$ FDLQhHXYnsw3AsVLfATwCt1SRWeb

[4] Meili (2010, August). A Probe into the Repetitive Discourse Patterns and Pragmatic Functions in Spoken Chinese. Retrieved from https://kns.cnki.net/kcms/detail/detail.aspx?dbcode $=$ CJFD \&dbname $=$ CJFD2010\& filename $=$ DDYY20 $1004054 \& v=A e B \% 25 \mathrm{mmd} 2 \mathrm{FwE} 3 \mathrm{FS} 3 \mathrm{aOwvtYAY}$ 7ZunO0aeGTH0otFcCfgxwtSV8wSnR4vsDC0sR RMQXX9\%25mmd2Fip

[5] Han, Q., Zhou, Z, K., \& Hu, W. P. The Influential Factors of Classroom Interaction and Teaching Revelation [J]. Theory and Practice of Education, 2008(16):42-45.

[6] Wheeler, R. W., Baron, J. C., Michell, S., \& Ginsburg, H. J. (1979). Eye contact and the perception of intelligence. Bulletin of the Psychonomic Society, 13(2), 101-102.

[7] Rosa, S. B. Understanding the Role and Potential Impact of Nonverbal Communication in the Primary Inclusion Classroom. The Annual Meeting of the Eastern Educational Research Association. Sarasota, FL, February27-March2, 2002, 19.

[8] Hodge, R. L. Interpersonal classroom communication through eye contract [J]. Theory into Practice, 1971, 10(4):264-267.

[9] Khan, N., Mohammad, N., Shah, N., Irfanullah. \& Farid, N. A Study of the Use of Eye Contact in Teaching-Learning Process at Secondary Level in District Peshawar [J]. Language in India, 2016, 16(4):81-98.

[10] Gu, Z, H. The Role of Eye Contact in a Classroom Setting-From an Intercultural Perspective. Overseas English, 2020, (24), 270-272+282.

[11] Xu, F., \& Xiong, H, P. The Theory of Classroom Visual Communication between Teachers and Students. Research in Educational Development, 2016, 36(02), 71-75

[12] Judy, F., Susan, M. (2011). Assessing comprehension: A classroom-based process. Retrieved from https://ila.onlinelibrary.wiley.com/doi/epdf/10.159 8/RT.60.5.1

[13] Youngju, L., Mable, B. K. (2012). Teacher question and student response with regard to cognition and language use. Retrieved from https://link.springer.com/content/pdf/10.1007/s112 51-011-9193-2.pdf

[14] Patrícia, A. A. (2011). Can I ask a question? the importance of classroom questioning. Retrieved from https://www.sciencedirect.com/science/article/pii/S $187704281103045 \mathrm{X}$ 